Military Technical College, Kobry El-Kobbah, Cairo, Egypt

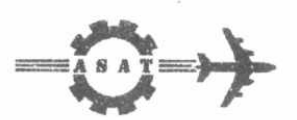

$9^{\text {th }}$ International Conference On Aerospace Sciences \& Aviation Technology

\title{
HEAT TRANSFER TO A TANGENTIALLY INJECTED SWIRL FLOW THROUGH AN ARTIFICIALLYY ROUGHENED ANNULUS
}

\author{
S.A. ABDEL-MONEIM", A.R. EL-SHAMY“"AND N.S. BERBISH"
}

\begin{abstract}
This paper provides heat transfer enhancement and flow friction data for swirl flows enter tangentially to an annulus roughened with helical-ribs. The effects of the roughness intensity, tangential to total momentum flux ratio and Reynolds number were studied. The tested annulus has a radius ratio of 0.25 with the inner surface insulated and the outer one was heated with a uniform heat flux. The inner surface of the outer tube was roughened with helically coiled wires which act as turbulence promoters breaking up the viscous sublayer formed in the fluid region nearest to the wall. Roughness was made by using helical-wires at two different diameter to pitch ratios $(d / p)$ of 0.025 and 0.050 within a range of Reynolds number from $5 \times 10^{3}$ to $25 \times 10^{3}$, and at vaiues of the tangential to total momentum flux ratios of $1.73,2.94$, 3.46 and 5.88 . It was found that there is a significant enhancement in the heat transfer due to inlet injection swirl compared with that gained by helical roughness. Also, the efficiency index is critically dependent on the roughness Reynolds number, momentum flux ratio and the roughness intensity and it is almost less than that for the rough plain annulus. New correlations for Nusselt number enhancement ratio and the Fanning friction factor ratio were obtained as functions of Reynolds number, momentum flux and $\mathrm{d} / \mathrm{p}$ ratios. Also, a maximum Nusselt number enhancement ratio of about 2.0 was found corresponding to 8.7 fold increase in the flow friction factor for a single entry injector with $M_{t} / M_{T}$ of 5.88 at relatively dense roughness with $d / p$ of 0.05 .
\end{abstract}

KEYWORDS: Heat transfer augmentation, fiow friction, forced convection, tangential-injected swirl flow, rough annulus, helical ribs

* Associate Prof., Mech. Eng. Dept., Faculty of Engineering, (Shoubra), Zagazig Univ. To whom correspondence should be addressed E-mail: sayed_moneim@hotmail.com ** Lecturers, Mech. Eng. Dept., Faculty of Eng., (Shoubra), Zagazig Univ. Cairo, Egypt 


\section{NOMENCLATURE}

SI units were applied for the whole parameters enclosed within this paper.

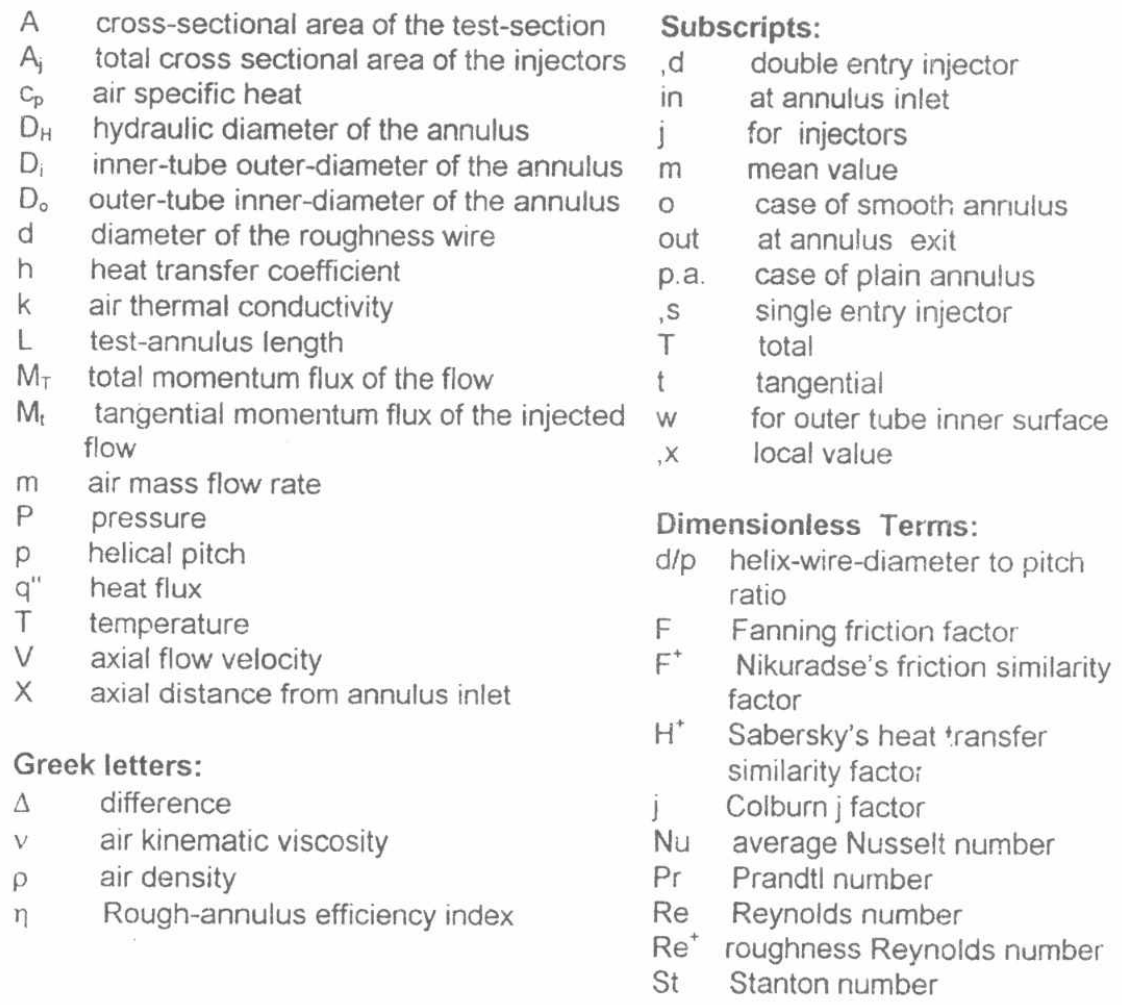

\section{INTRODUCTION}

Heat-transfer enhancement in internal flow forced convection may be in general divided into two categories. The first involves incorporating grooves, protrusions and helically coiled wire on the flow passage walls. The presence of roughness elements creates additional turbulence and eddies that disrupt the laminar sublayer and improves the heat transfer. The second enhancement strategy involves the insertion of turbulence promoters such as tubular injectors at inlet to the flow passages. Swirl flow improves heat transfer not only by increasing the overall flow turbulence, but also by promoting the exchange of heat and momentum between the higher momentum flow region and the wall region.

In fact, annular flow passages are commonly encountered in engineering heat exchange systems such as pressurized heavy water nuclear reactors. Therefore, 
improved heat transfer coefficient in annulus flow is considered a real challenge and an importunate problem that facing engineers. Numerous theoretical and experimental studies have been carried out for flow and heat transfer in smooth piain annular geometries. However, few of previous studies, summarized by Kalinin and Dreitser [1] and Webb [2], have been carried out on enhanced annular surfaces incorporating either inner grooved or finned tubes with transverse and helical ribs. Measurements of the flow losses and the convective heat transfer in a ribbed coresmooth annulus were carried out by Romero [3] where the ribbing had been partially or totally removed from relatively small locations. The results showed that the local impairment might, in some instances, be worse than that expected from correlations of heat transfer which apply to uniformly reduced ribbing. On the other hand, at low flow velocities, where the ribs cease to have a large effect on the flow, the heat transfer due to the reduced ribbing was better than might have been expected. Turbulent heat transfer in an internally heated annular space with artificial outer wall roughness was studied by Muhlenbruch et al. [4,5]. Abdel-Moneim et al. [6] carried out an experimental study to investigate the heat transfer and flow friction in an artificially roughened annulus with the inner surface insulated and the outer one was heated with a constant heat flux and roughened with helically coiled wires. The fully developed turbulent momentum and heat transfer in concentric annuli with artificial roughness elements on the inner, outer and both walls for three radius ratios of 0.26 , 0.39 and 0.56 were experimentally and analytically studied by Ahn and Kim [7]. The flow mean velocity profile, friction factor, position of the maximum velocity and zero shear stress were measured with a Pitot tube and an X-type anemometry system. It was found that certain artificial roughness elements might be used to enhance heat transfer rates advantageously from the overall efficiency point of view. Takase [8] and Takase and Akino [9] investigated the thermal-hydraulic characteristics in two and three dimensional (2D \& 3D) rib-roughened annuli at high temperature and pressure. The thermal performance of the square-ribbed annuli was compared with that of the spacer-ribbed annulus and the following results were found:

1-The heat transfer coefficients (HTCs) and the friction factors for a spacer-ribbed annulus with 3D roughness increased by about $20 \%$ in comparison with those of a smooth annulus.

2- In the turbulent region, the HTCs and friction factors in the square-ribbed annulus with different rib height to pitch ratios were higher by about $50 \%$ than those in the spacer-ribbed annulus.

3-The HTCs in the square-ribbed annulus indicated a feature in the transition region for $R e<3000$, as in the case of a smooth annulus.

4-The roughness parameter in the square-ribbed annulus approached the value of the hydraulically smooth region as Re decreased.

Heat transfer measurements were performed by Hsieh and Wen [10] on six rib-type roughened tube annuli (4.67-9.01 $\mathrm{mm} \mathrm{D}_{\mathrm{H}}$, rib pitch 19.7-63.0 mm, rib height $4 \mathrm{~mm}$, rib width $15 \mathrm{~mm}$, rib angle 20-60 deg.) with two phases of refrigerant R-114 under evaporating conditions. The effect of the rib spacing on flow boiling heat transfer coefficient was studied and correlations for both the enhancement factor and the suppression factor were developed. 
Akansu et al. [11] studies experimentally and theoretically the heat transfer characteristics in the entrance region of an annuls with varying cross- section by using liquid crystal technique. Measurements were made at Reynolds numbers ranging from 14000 to 45000 based on the average inlet velocity and hydraulic diameter. It was found that, the local Nusselt number initially decreases, passing a minimum value at a certain position, then increases along the annulus again. This phenomenon was emphasized and the position of minimum Nusselt number became closer to the inlet of the annulus with the increase in Reynolds number.

Garimella and Christensen [12] studied the flow mechanisms and pressure drop in annuli with spirally fluted inner tubes for the laminar, transition, and turbulent regimes. From the variation of friction factor as a function of Reynolds number, it was found that transition in these annuli occurs in the $310<\mathrm{Re}<1000$ range. Friction factor increases were typically between 1.1 and 2.0 in the laminar regime and up to 10 in the turbulent regime. The friction factors were found to be functions of flute depth, pitch, angle and the annulus radius ratio. Garimella and Christensen [13] studied the heat transfer and pressure drop in annuli with spirally fluted inner tubes for the laminar, transition, and turbulent flow regimes. A wide variation in all the relevant geometric parameters was achieved. They found that Nusselt numbers in spirally fluted annuli are between 4 and 20 times higher than the corresponding smooth annulus values in laminar flow due to the induced swirl flow. For turbulent flow, the enhancement is between 1.1 and 4.0. Also, the fluted annulus Nusselt number increases with an increase in flute depth, and with a decrease in flute pitch and annulus radius ratio. Chiou [14] carried out an experimental investigation of a class of spiral spring coil used as heat transfer augmentative device in the cooling of oil flow. Chiou found that the spiral spring insert could increase the tube side heat transfer coefficient significantly. For the same fluid pumping power requirement, the heat transfer coefficient of the oil flow in a tube with this type of spring insert can triple that obtained in a tube without augmentative device (bare tube) when the Reynolds number is lower than about 1,200. As the Reynolds number increases, the enhancement effect decreases asymptotically,

Heat transfer measurements and predictions were performed in an annulus with axial flow and inner tube rotating by Nijaguna and Mathiprakasam [15] and Karasu [16] to investigate the effect of the rotating flows on the heat transfer characteristics. Abdel-Moneim et al [17] studied experimentally the heat transfer enhancement and flow friction for a swirl flow that enters tangentially in a tube roughened by helical ribs. It was found that the efficiency index is critically dependent on the roughness Reynolds number and it is almost less than that for the rough plain tubes.

In view of the reviewing of the literature, the effect of the generated swirling flow in roughened tube annuli on both heat transfer and flow friction has not been studied extensively. Therefore, the present work is proposed, as an extension for a series of heat transfer augmentation studies that have been carried out by Abdel-Moneim et al. $[6,17,18]$, for the purpose to explore some aspects of single phase heat transfer and flow friction for the injection created swirl flow in annuli roughened with helical ribs. 


\section{EXPERIMENTAL APPARATUS}

The entire apparatus shown schematically in Fig.(1) consists mainly of an open-air flow circuit, the test-annuiar section including the roughness coil, tubular injectors and measuring instruments. The test-section is a concentric-tube annulus with an aspect ratio $\left(D_{j} / D_{0}\right)$ of 0.25 in which only the inner surface of the outer tube is roughened. Heat is only transferred from the inner surface of the outer tube while the inner tube is kept adiabatic. The outer tube is made of brass with $40 \mathrm{~mm}$ inner diameter, $3 \mathrm{~m}$ long and $3.5 \mathrm{~mm}$ thickness. The inner tube is a thin stainless steel pipe of $10 \mathrm{~mm}$ outer diameter filled with asbestos as an insulating material. A hydrodynamic entry length of $2.5 \mathrm{~m}$ is allowed upstream of the tubular injectors which are located individually at the test-section inlet. The test section is heated by means of an electric heater and a guard heater is also used to prevent heat loss. The roughness is formed by winding a long wire of stainless steel of $1 \mathrm{~mm}$ diameter with a predetermined pitch on a removable wetted-wooden rod of $37.5 \mathrm{~mm}$ diameter using a precision lathe. The roughness coil is fitted tightly on the outer tube inner surface by its expansion due to the winding stiffness as shown in Fig. $(1-b, c)$. The helical pitch is assumed unaffected by coil expansion as the clearance between the removable rod and the tube inner surface is kept very small. To avoid deformation in the roughness coil due to the sliding of the removable wooden rod the heaters are switched on to elevate the tube temperature and to dry the rod in order to increase the clearance between the rod and the roughness coil. This makes it easy to withdraw the rod without any disturbance to the roughness coil pitch.

Air as a working fluid was injected tangentially through a set of tubular injectors with two different injection-tube inner diameters of 16.5 and $21.5 \mathrm{~mm}$, respectively. The injectors were fabricated and assembled such that two injection-tubes with $150 \mathrm{~mm}$ length for each were fixed tangentially and opposed diametrically on a base tube of $300 \mathrm{~mm}$. length and $40 \mathrm{~mm}$ inner diameter (the same inner diameter of the testsection). Also, the injection-tubes were fixed perpendicular to the base tube axis. The injector's base tubes were connected individually to the inlet end of the test annulus via a short flexible connection. Details for one of the used injectors are
shown in Fig.(1-d).

The temperature of the inner surface of the outer tube of the annulus was measured at 40 different axial locations distributed along the test-section with relatively high concentration through the entrance region. To check the axisymetry of the flow, two diametrically opposite top-bottom, thermocouples were fixed at each test location. The used thermocouples were made of copper-constantan wires with $0.5 \mathrm{~mm}$ diameter and connected to a digital thermometer having one decimal point (sensitive to $0.1^{\circ} \mathrm{C}$ ). The air flow radial temperature profile is measured via radiation-shielded thermocouples mounted on vertical traverse mechanisms at annulus inlet and exit, respectively. To avoid flow disturbance, each of the thermocouples probe with its shield is resided in a tubular cavity that is assembled normal to the test annulus such that the probe is presented only in the flow field at the instant of reading.

The air flow rate is measured by a calibrated orifice and the reading of its head difference is indicated by an inclined differential manometer. Also, U-tube manometers are used for measuring the axial pressure distribution alsong U-tube
section. 


\section{EXPERIMENTAL PROCEDURE AND METHOD OF CALCULATIONS}

Air is admitted into the test annulus through different injectors with either double or single entry to perform different values of momentum flux ratio. The momentum flux ratio is the ratio between the momentum flux of the injected flow through the injectors and the total momentum flux through the test-annulus and it can be expressed by:

$$
\frac{M_{t}}{M_{T}}=\frac{m_{t}^{2} A}{m_{T}^{2} A_{j}}
$$

In the present experiments the total mass flow rate of working fluid is injected tangentially to the test section. Herice the ratio $m_{t} / m_{T}$ is equal to unity and consequently the momentum flux ratio can be simply expressed by the area ratio $A / A_{j}$. Therefore, values for the momentum flux ratios of 1.73 and 3.46 are assigned corresponding to double and single entry injectors of $21.5 \mathrm{~mm}$ diameter while values of 2.94 and 5.88 are assigned for double and single entry injectors of $16.5 \mathrm{~mm}$ diameter, respectively.

The local heat transfer coefficient along the test annulus, which is divided into 16 axial segments with its lengths conceritrated at the entrance region, is caiculated by,

$$
h_{x}=\frac{q^{\cdot}}{T_{w, x}-T_{1, x}}
$$

where

$q^{\prime \prime}$ is the heat flux, calculated from the readings of the main heater circuit (voltage, current and power factor) and the outer-tube surface area.

$T_{w, x}$ is mean temperature of the inner surface of the outer tube of the annulussegment (the mean value between the top and bottom thermocouples readings)

$T_{f, x}$ is the local flow bulk temperature at the annulus segment, calculated from the heat balance for each, segment and checked with the mean value calculated by integrating the measured radial temperature profiles at inlet and exit, respectively.

The average Nusselt number based on the hydraulic diameter is calculated by,

$$
N u=\frac{1}{L} \int_{x=0}^{L} \frac{h_{x} D_{H}}{k} d x
$$

Also, Stanton number $S t=\frac{\mathrm{Nu}}{\operatorname{RePr}}$, the flow Reynolds number, $\operatorname{Re}=\frac{V D_{H}}{v}$ and PrandtI number, $\operatorname{Pr}$ are calculated while the fluid properties are evaluated at the flow bulk temperature, $\left(T_{\text {in }}+T_{\text {out }}\right) / 2$.

The flow friction in terms of Fanning friction factor is estimated from the measurements of the pressure drop along the test section as: 


$$
F=\frac{\Delta P}{2 \rho V^{2}} \frac{D_{H}}{L}
$$

Moreover, the flow friction and heat transfer data are reformulated in terms of Nikuradse's friction similarity factor $\mathrm{F}^{+}$and Dipprey and Sabersky's heat transfer similarity factor $\mathrm{H}^{+}$which have been reported by Abdel-Moneim and Co-workers $[6,17,18]$ and expressed as follows:

$$
\begin{aligned}
& F^{*}=\sqrt{\frac{2}{F}}+2.5 \ln \left(\frac{2 d}{D_{H}}\right)+3.75 \\
& H^{+}=\left(\frac{F}{2 S t}-1\right) / \sqrt{\frac{F}{2}}+F^{+}
\end{aligned}
$$

The efficiency index, which is defined by the ratio between the Stanton number enhancement ratio $\left(S t / S t_{0 . p . a .}\right)$ to the friction factor ratio $\left(F / F_{0 . p . a}\right), \eta=\frac{S t / S t_{0 . p . a}}{F / F_{0 . p . a .}}$ is an important criterion in evaluating any technique for heat transfer enhancement. The roughness Reynolds number $\mathrm{Re}^{+}$, based on the roughness wire diameter, is also . calculated as:

$$
\operatorname{Re}^{+}=\operatorname{Re} \frac{d}{D_{H}} \sqrt{\frac{F}{2}}
$$

\section{RESULTS AND DISCUSSION}

As a verification of the experimental procedure and measuring instruments, preliminary experiments were conducted for the flow in a smooth plain-annulus within a range of Reynolds number from $10 \times 10^{3}$ up to $50 \times 10^{3}$. The heat transfer results, in terms of Nusselt number, of these preliminary experiments were compared with previously published correlations $[6,13]$ and fair agreement was found as shown in Fig. (2-a). Beside establishment of the present experimental technique these preliminary experiments were carried out to perform references for comparison to evaluate the effect of the tangentially injected swirl flow in the roughened annuli. Also, the case of the smooth annulus was experimented for a tangentially injected swirl flow at different values of $M_{t} / M_{T}$ ratio $(1.73,2.94,3.46$ and 5.88$)$ and the results are presented in Fig.(2-a). Generally, the average Nusselt number values for the smooth annulus with inlet swirl are higher than that for plain annulus flow. This may attributed to that superimposition of the tangential velocity influences the velocity distribution and the flow turbulence and in accordance enhances the heat transfer.

The present results for the Fanning friction factor for the smooth plain annulus were compared with the correlation's of $[6,12]$ within the investigated range of Reynolds number and fair agreement was found as shown in Fig.(3-a). Higher values of the Fanning friction factor were observed for the tangentially injected swirl flow in 
smooth annulus compared with those of the smooth plain annulus as shown in Fig.(3-a). To clarify the enhancing effect of the inlet swirl, the Colburn jfactor $\left(j=S t \mathrm{Pr}^{\frac{2}{3}}\right)$ was calculated and plotted versus Reynolds number for the flow in smooth annulus at different $M_{\mathrm{t}} / \mathrm{M}_{\mathrm{T}}$ ratios as shown in Fig.(4-a). Normal and expected enhancement in the heat transfer due to tangentially injected swirl was observed. In order to investigate the effect of roughness, experiments were carried out at two different $\mathrm{d} / \mathrm{p}$ ratios of 0.025 and 0.050 . The variations of the average Nusselt number at different $M_{t} / M_{T}$ and at the two different $d / p$ ratios are shown in Fig. $(2-b, c)$. respectively. An appreciable enhancement in the Nusselt number was obtained, in general, due to the presence of either the roughness or the inlet swirl. In fact, the presence of the roughness helical-coil conserves the swirl and the secondary flows that created by the tangential injection for a longer distance. This increases the actual flow pass, influences the flow turbulence and in so doing enhances the heat transfer coefficient. This effect becomes more dominant for the annulus with dense roughness, $(d / p=0.05)$, as shown in Fig. $(2-c)$. The effect of the injection entry condition (single or double entry according to the ratio $M_{T} / M_{T}$ ) on the average Nusselt number is also, presented in Fig.(2). It was found that, single entry injectors enhance the heat transfer more than the double entry injectors at the same injected mass flow rate.

Figure $(3-b, c)$ presents the Fanning friction factor for rough annulus with inlet swirl versus Reynolds number. Generally, higher values for the friction factor were found compared with those of the smooth plain annulus. In fact, due to the combined effects of both the helical roughness and the tangential entry, longer helical flow passage was existed in the wall laminar sublayer and higher friction factor was expected. Also, in a similar manner as in the heat transfer, it was found that the increase in the friction factor for the single entry injectors is extremely higher than that for the double entry injectors.

As depicted in Fig. (4), higher values for the Colburn $j$ factor were found for the tangentially injected swirl flow in both smooth and rough annuli. This confirm the enhancing effects of the injected swirl flow.

Figure (5) shows the variation of the friction similarity factor $\left(\mathrm{F}^{+}\right)$with the roughness Reynolds number $\left(\operatorname{Re}^{+}\right)$at different $d / p$ and $M_{t} / M_{T}$ ratios. The present results indicate that $\mathrm{F}^{+}$increases with $\mathrm{Re}^{+}$till it approaches an asymptotic value depending on both $\mathrm{d} / \mathrm{p}$ and $\mathrm{M}_{\mathrm{t}} / \mathrm{M}_{\mathrm{T}}$ ratios. Also, the asymptotic value of $\mathrm{F}^{+}$decreases with the increase in either the $d / p$ or $M_{t} / M_{T}$ ratios. Moreover, the value of $R^{+}$at which $F^{+}$reaches its asymptotic value decreases with increasing the ratio $M_{t} / M_{T}$.

The heat transfer similarity factors $H^{+}$versus $\mathrm{Re}^{+}$at different $d / p$ and $M_{t} / M_{T}$ ratios are presented in Fig.(6). On contrast to the behavior of $\mathrm{F}^{+}, \mathrm{H}^{+}$decreases with $\mathrm{Re}^{+}$and this implies the enhancement in the heat transfer.

The roughness efficiency index was employed to evaluate the performance benefits of the rough annulus and the results are shown in Fig.(7). It was found that the roughness efficiency index for the plain annulus is almost greater than that for the tangentially injected flow regardless the value of $d / p$ ratio. Also, the efficiency index is critically dependent on $\mathrm{Re}^{+}$and it reaches its maximum at a value of $\mathrm{Re}^{+}$ depending on both $d / p$ and $M_{t} / M_{T}$ ratios. 
As in the case of tube flow [17], single entry injectors give lower efficiency indices compared with those of the double entry injectors as shown in Fig. (7). However, single entry injectors enhance the heat transfer more than the double entry injectors, unfortunately, the flow friction extremely increases due to the higher incoming-flow velocity. Therefore, lower efficiency indices were obtained compared with those of double entry injectors

The Nusselt number enhancement ratio and the Fanning friction factor ratio were correlated utilizing the present experimental data and the following correlations were obtained:

where,

$$
\frac{\mathrm{Nu}}{N u_{\text {op.a. }}}=R e^{0.03}\left(\frac{d}{p}\right)^{0.025}\left(\frac{M_{t}}{M_{T}}\right)^{0.27}
$$

$$
\mathrm{Nu}_{\text {o,p.a. }}=0.0196 \mathrm{Re}^{0.8}
$$

This correlation is accurate to approximately $\pm 18 \%$ for about $90 \%$ of the present experimental data within the investigated range of the different parameters

Also,

where,

$$
\frac{F}{F_{\text {opp. }}}=15.15\left(\frac{d}{p}\right)^{0.5}\left(\frac{M_{t}}{M_{T}}\right)^{0.538}
$$

$$
F_{\text {o.p.a. }}=0.0709 \operatorname{Re}^{-0.2}
$$

This correlation is also accurate to approximately $\pm 10 \%$ for $95 \%$ of the present experimental data within the investigated range of Reynolds number from 5,000 up to 25,000 for the two helix wire diameter to helical pitch ratios of 0.025 and 0.050 . and for momentum flux ratios ranging between 1.73 and 5.88 .

\section{CONCLUDING REMARKS}

The main findings based on the present measurements are as follows:

1- It was found that the turbulence created from the presence of the helical rib and the increase in the flow turbulence due to the tangential inlet swirl augments the heat transfer in general.

2- A maximum Nusselt number enhancement ratio of about 2.0 corresponding to a 8.7 fold increase in the friction factor was obtained for the annulus with $d / p=0.050$ at $R e$ of about 8,300 for single entry injector with $M_{t} / M_{T}=5.88$.

3- The efficiency index is critically dependent on $\mathrm{Re}^{+}$and it was generally, less than that for plain annulus flow.

4- As in the case of tube flow [17], the results for roughened annulus with inlet injection flow show that the efficiency index for double entry injectors was greater than that for single entry injectors. 
5- The swirl associated with the tangential entry was conserved for a long distance through the dense roughened annulus that apparently enhances the heat transfer but unfortunately it increases the flow friction with a higher extent. Therefore, lower efficiency indices were obtained for this case.

6- A maximum value of 0.33 for the efficiency index was found for the annulus with a double entry injector at relatively low roughness density $(d / p=0.025)$.

\section{REFERENCES}

[1] Kalinin, E.K. and Dreitser, G.A., "Heat Transfer Enhancement in Heat Exchangers", Advances in Heat Transfer, Vol. 31, pp.159-332, (1998).

[2] Webb, R.L., "Principles of Enhancement Heat Transfer", Chapter 8, John Wiley \& Sons Inc., New York, (1994).

[3] Romero, E., "Perturbation of the heat transfer and the friction factor of a rib roughened surface in an annular passage due to localized removal of the ribbing", Nuclear Engineering and Design, Vol. 188, No. 1, pp.85-96, (1999).

[4] Muhlenbruch, G., Boye, H., Kuhne, S. and Schmidt, J., "Turbulent heat transfer in an internally heated annular space with artificial outer wall roughness", Chemie Ingenieur Technik, Vol.70, No.11, pp.1412-1416, (1998).

[5] Muhienbruch, G., Boye, H., Kuhne, S. and Schmidt, J., "Turbulent heat transfer in inner heated annuli with artificially roughened outer walls", Chemical Engineering \& Technology, Vol.22, No.1, pp.26-30, (1999).

[6] Abdel-Moneim, S.A., El-Shamy, A.R. and Atwan, S.F., "Experimental Study of Heat Transfer and Flow Friction in Artificially Roughened Annulus", Proceedings of Cairo $7 \underline{t h}$ Int. Conf. on Energy and Environment, Vol. 1, pp 371385, Cairo, Egypt, March (2000).

[7] Ahn, S.W., and Kim, K.C., "Fully developed fluid flow and heat transfer in rough annuli", Int. Communications in Heat and Mass Transfer, Vol.25, No 4, pp.501-510, (1998).

[8] Takase, K., "Experimental results of heat transfer coefficients and friction factors in a 2D/3D rib-roughened annulus", Experimental Thermal and Fluid Science, Vol.13, No.2, pp.142-151, (1996)

[9] Takase, K. and Akino, N., "Numerical Simulation of Turbulent Heat Transfer in an Annular Fuel Channel Augmented by Spacer Ribs", Proceed. of $30^{\text {th }}$ Intersociety Energy Conversion Eng. Conf., Vol. 2, pp.225-230, (1995).

[10] Hsieh, S.S. and Wen, M.Y., "Experimental-Study Of Flow Boiling Heat-Transfer In rib-Roughened Tube Annuli", ASME, J. of Heat Transfer, Vol.117, No.1, pp.185-194, (1995).

[11] Akansu, Y.E., Tahir Y. and Kemal K., "Experimental Determination of the Heat Transfer and Flow Characteristics in the Annular Geometries with Variable Cross Section", 11th International Mechanical Power Engineering Conference, Cairo, Vol. 1, pp. H13-H27, Feb. (2000). 
[12] Garimella, S. and Christensen, R.N., "Heat Transfer and Pressure Drop Characteristics of Spirally Fluted Annuli: Part I-Hydrodynamics", ASME, J. of Heat Transfer, Vol. 117, pp. 54-60, Feb. (1995).

[13] Garimella, S. and Christensen, R.N., "Heat Transier and Pressure Drop Characteristics of Spirally Fluted Annuli: Part II-Heat Transfer", ASME, J. of Heat Transfer, Vol. 117, pp. 61-68, Feb. (1995).

[14] Chiou, J. P., "Experimental Investigation of the Augmentation of Forced Convection Heat Transfer in a circular Tube Using Spiral Spring Inserts", ASME, J. of Heat Transfer, Vol. 109, pp. 300-307, May (1987).

[15] Nijaguna, B.T. and Mathiprakasam, B., "Heat Transfer in An Annulus with Spiral Flows", Proceedings of the 7th Int. Heat Transfer Conf., Vol.3, pp.99-104, (1982).

[16] Karasu, T., "Prediction of Turbulent Flow with Heat Transfer in An Annulus with Rotating Inner Cylinder", Alternative Energy Sources VIII, Vol. 2, pp.361-386, (1989).

[17] Abdel-Moneim, S.A., El-Shamy, A.R. and Berbish, N.S., "Heat Transfer Enhancement in A Tangentially Injected Swirl Flow through A Roughened Tube", Proceedings of Al-Azhar Eng. 6th Int. Conf. AEIC2000, Vol.7, pp.175190, Sept. (2000).

[18] Abdel-Moneim, S.A. and El-Shamy, A.R., "Heat Transfer and Flow Characteristics in Helically Rib-Roughened Tubes", Proceedings of the 11 th Int. Mech. Power Eng. Conf. (IMPEC 11), Vol.1, pp.H60-H74 Cairo, Egypt, Feb. (2000). 


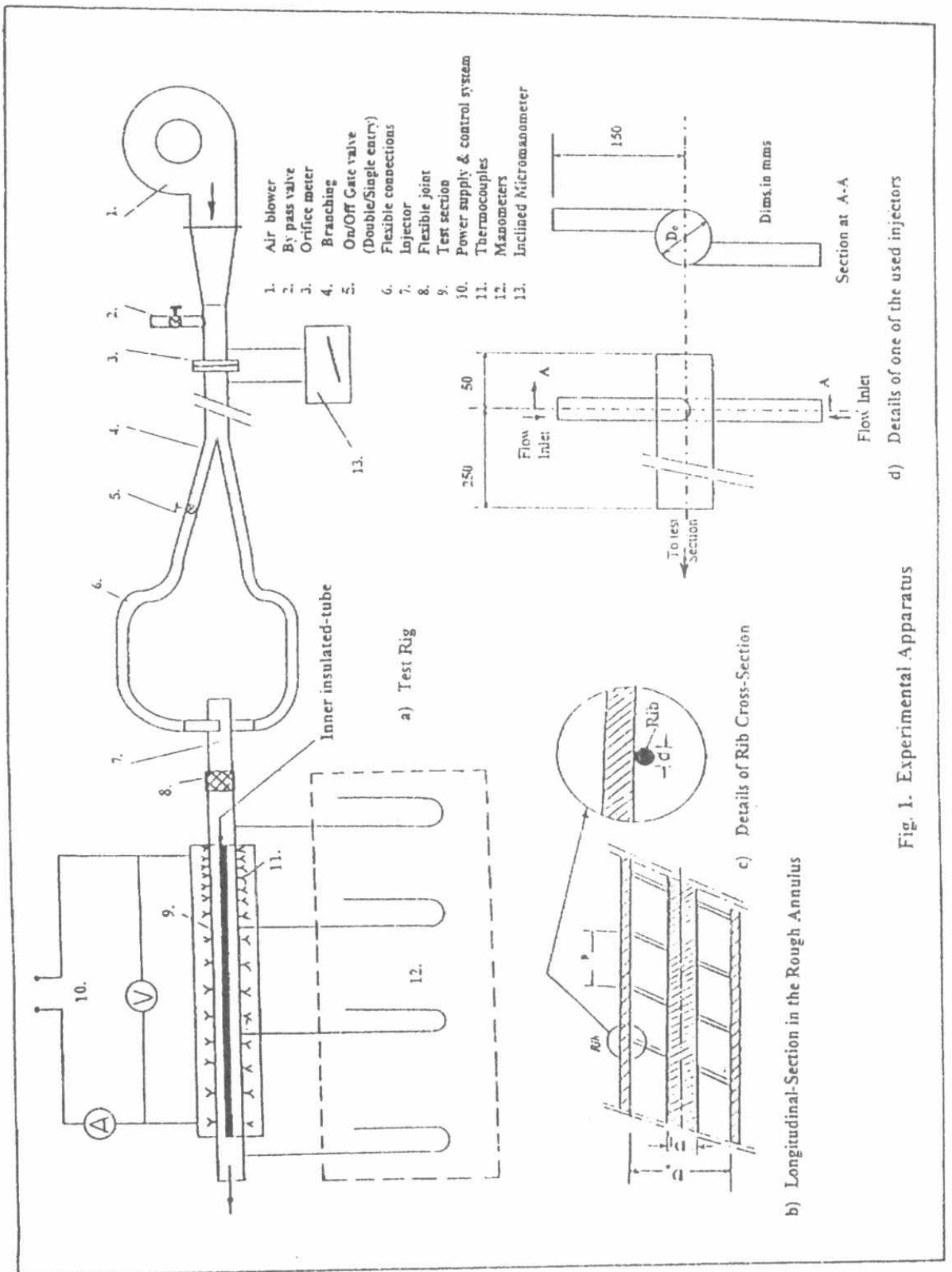




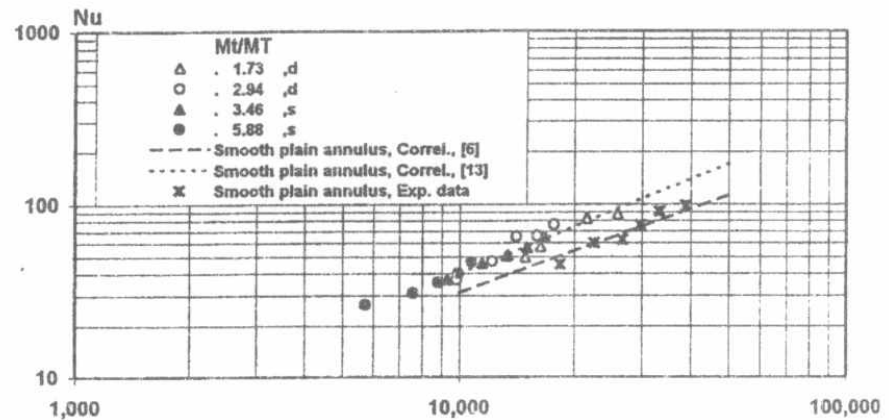

(a) Smooth annulus with inlet swirl

$\mathrm{Re}$

$\mathrm{Nu}$

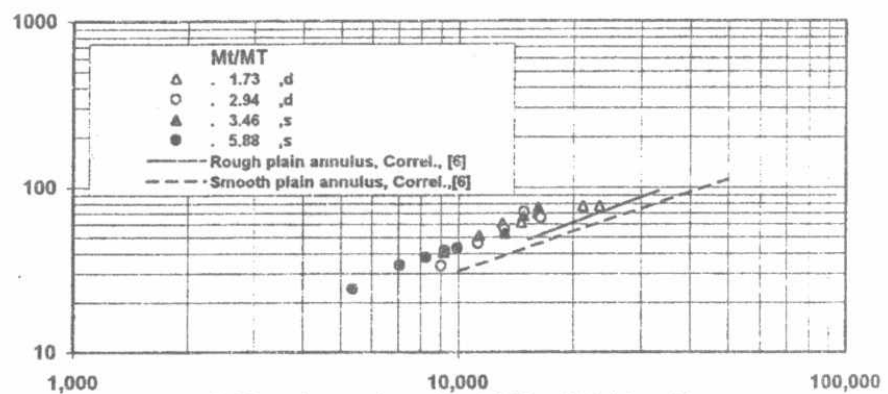

(b) Rough annulus, $d / p=0.025$, with inlet swirl

$\mathrm{Re}$

$\mathrm{Nu}$

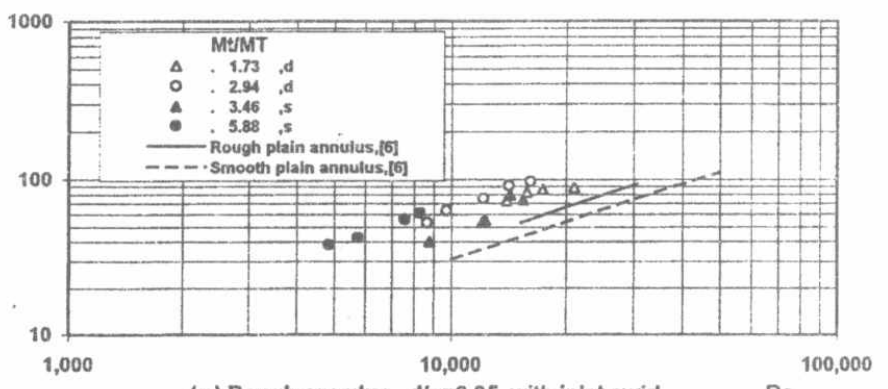

(c) Rough annulus, $d / p=0.05$, with inlet swirl

$\mathrm{Re}$

Fig. 2. Average Nusselt number versus Reynolds number for smooth and rough annuli 


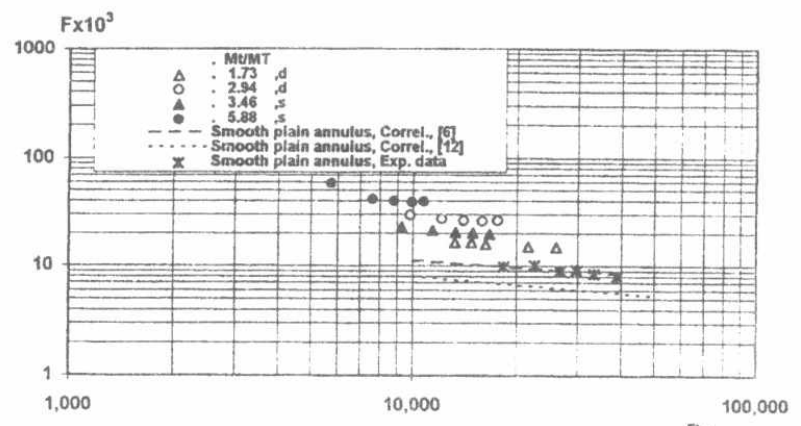

(a) Smooth annulus with inlet swirl

$\mathrm{F} \times 10^{3}$

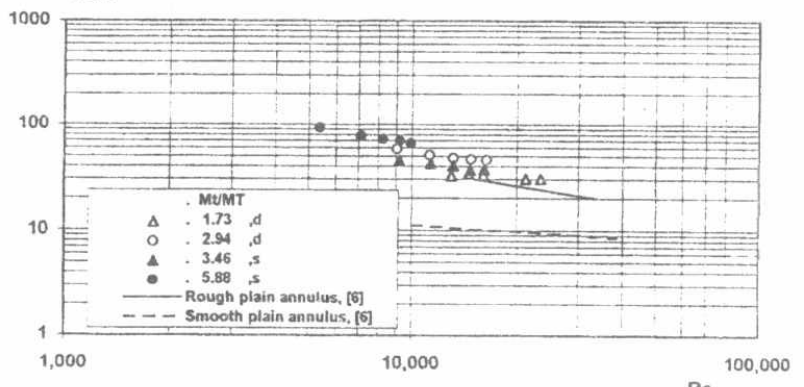

(b) Rough annulus, $d / p=0.025$, with inlet swirl

$\operatorname{Re}$

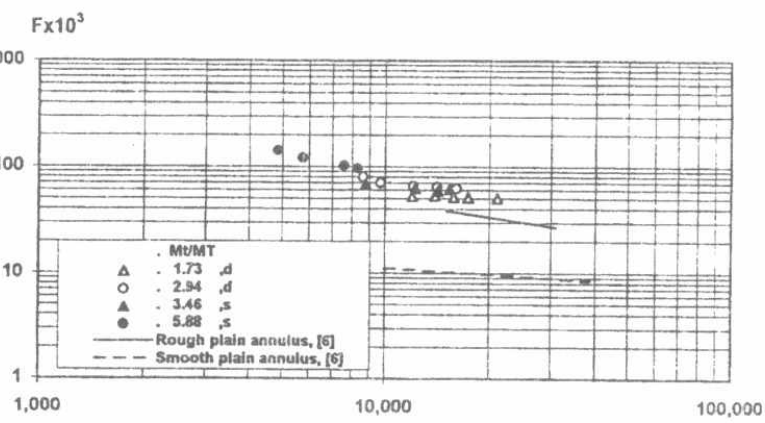

(c) Rough annulus, $d / p=0.05$, with inlet swirl

Re

Fig. 3. Fanninig friction factor versus Reynoids number for smooth and rough annuli 


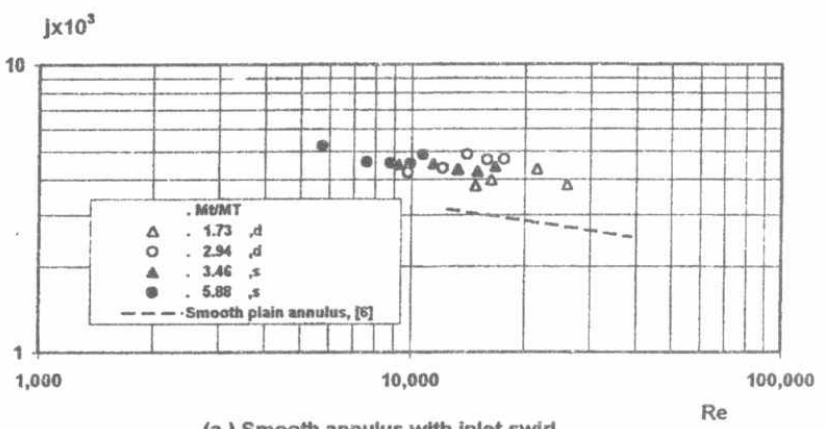

(a) Smooth annulus with inlet swir!

$\operatorname{Re}$

$\mathrm{j} \times 10^{3}$

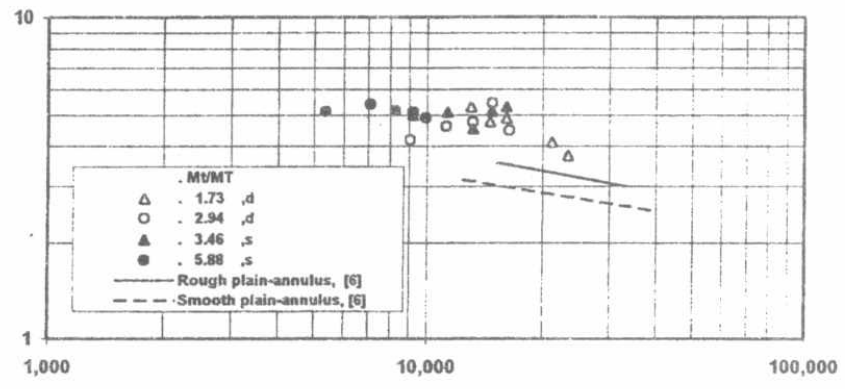

(b) Rough annulus, $d / p=0.025$, with inlet swirl

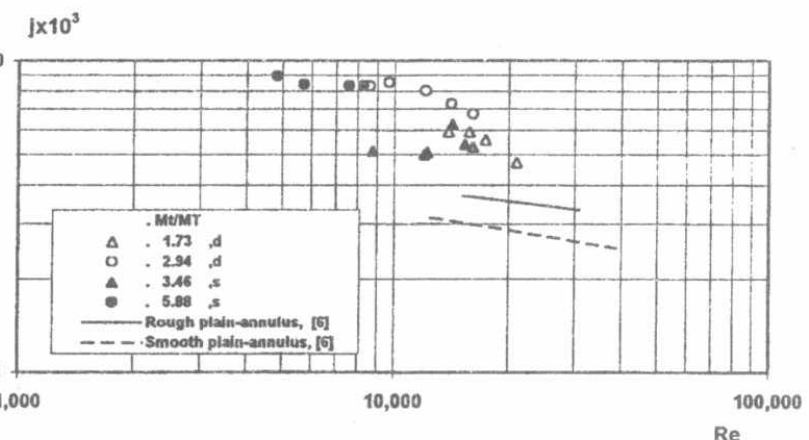

(c) Rough annulus, $\mathrm{d} / \mathrm{p}=0.05$, with inlet swirt

Fig. 4. Colburn j factor versus Reynolds number for smooth and rough annuli 


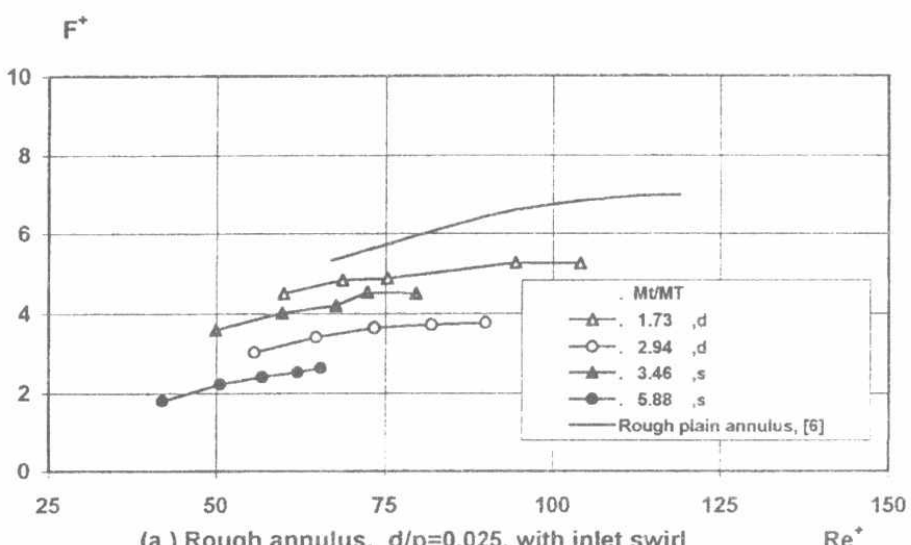

(a) Rough annulus, $d / p=0.025$, with inlet swirl

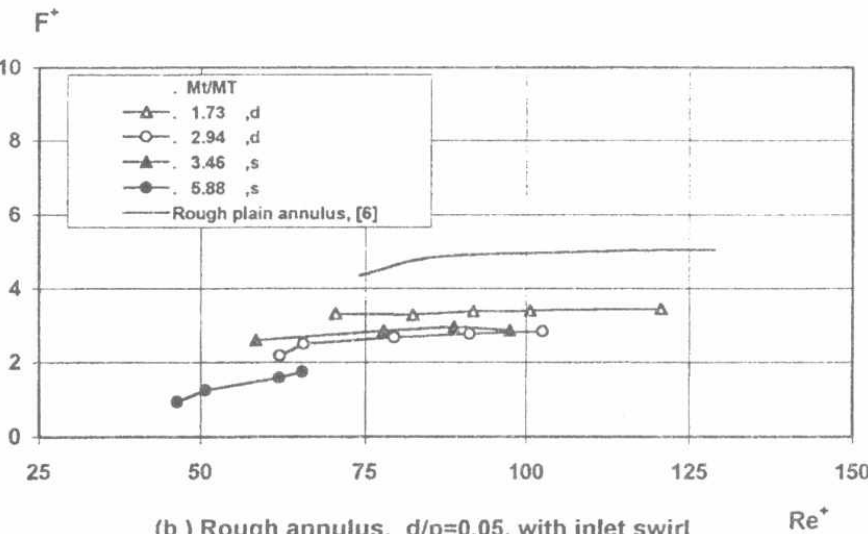

Fig. 5. Nikuradse's friction similarity factor versus roughness Reynolds number at different $d / p$ and Mt/MT ratios 


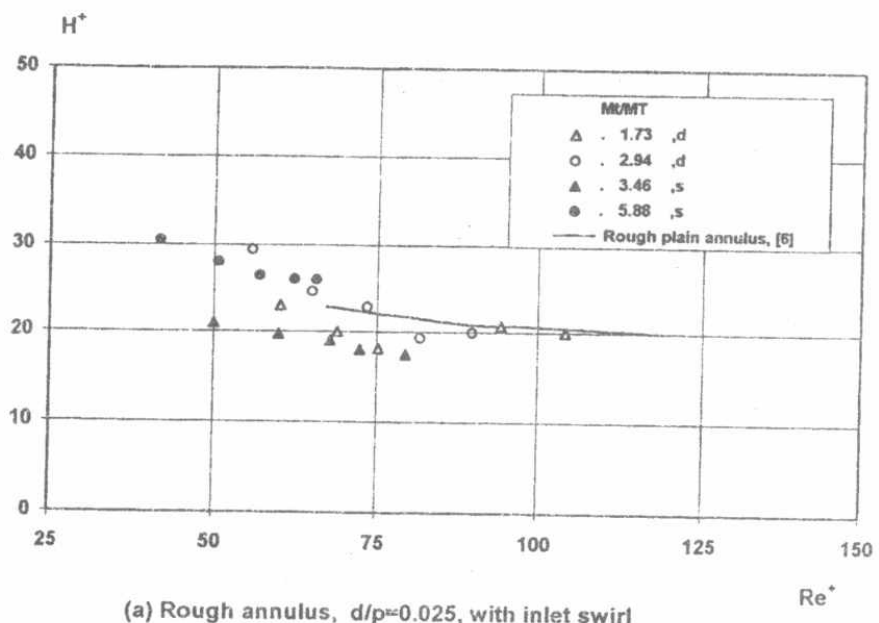

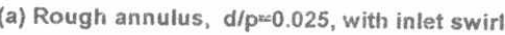

$\mathrm{H}^{+}$

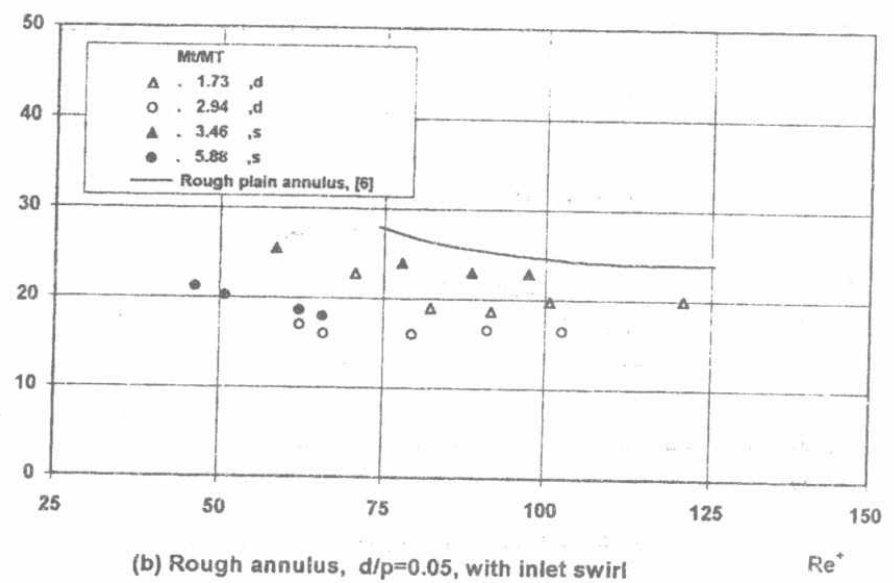

Fig. 6. Dipprey and Sabersky's heat transfer similarity factor versus roughness Reynolds number at different $d / p$ and Mt/MT ratios 


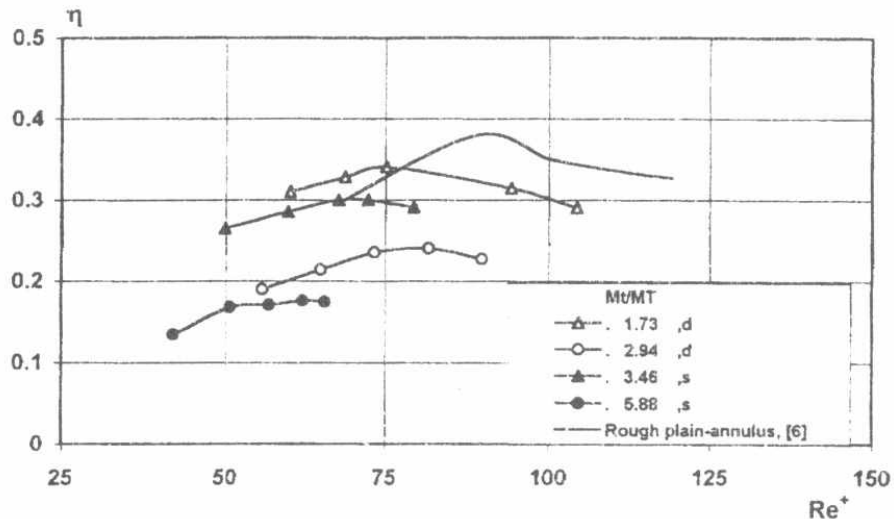

(a) Rough annulus, $d / p=0.025$, with inlet swirl

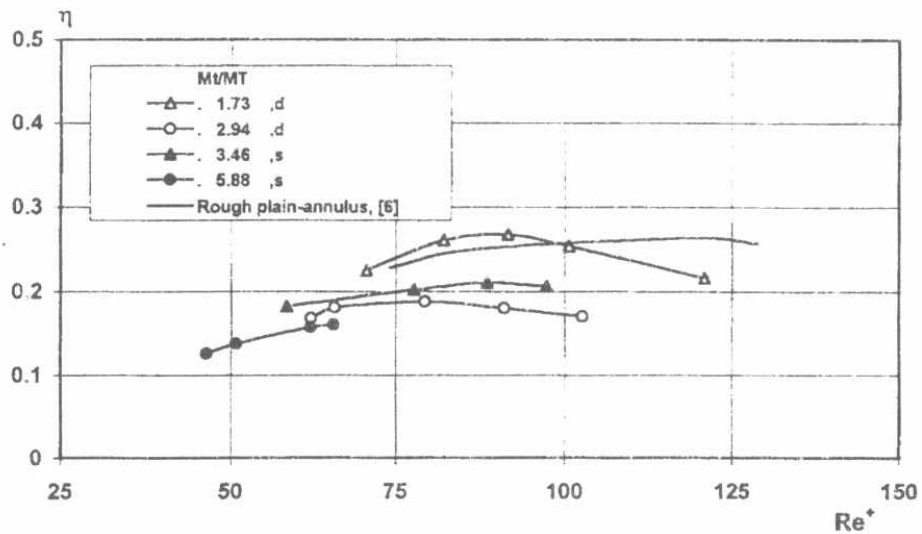

(b) Rough annulus, $d / p=0.05$, with inlet swir

Fig. 7. Rough annulus efficiency index versus roughness Reynolds number at different $d / p$ and Mt/MT ratios 